\title{
Production, Composition and Fuel Properties of Tallow Biodiesel: A Case of Botswana
}

\author{
Jerekias Gandure*, Clever Ketlogetswe, Mbako Jonas \\ Department of Mechanical Engineering, Faculty of Engineering and Technology, University of Botswana, Gaborone, Botswana \\ Email: ^gandurej@mopipi.ub.bw
}

How to cite this paper: Gandure, J., Ketlogetswe, C. and Jonas, M. (2017) Production, Composition and Fuel Properties of Tallow Biodiesel: A Case of Botswana. Energy and Power Engineering, 9, 355-365. https://doi.org/10.4236/epe.2017.97024

Received: May 2, 2017

Accepted: July 23, 2017

Published: July 26, 2017

Copyright $\odot 2017$ by authors and Scientific Research Publishing Inc. This work is licensed under the Creative Commons Attribution International License (CC BY 4.0).

http://creativecommons.org/licenses/by/4.0/ (c) (†) Open Access

\begin{abstract}
Biodiesel has been identified globally as presenting an opportunity for development of a sustainable fuel source, especially in light of international pressures for greenhouse gas emission reductions and the unpredictability of availability and pricing of fossil fuels. For Botswana, the internal development of biodiesel could signify a positive move away from a dependency on imported fuel products, provide sustainable employment and contribute to poverty alleviation measures. In the current study, biodiesel was synthesized from animal fat and tested for fuel properties. Results have shown a biodiesel production yield of $93 \%$, chemical composition that is typical of a biodiesel fuel, and fuel properties that are largely comparable to those of petroleum diesel.
\end{abstract}

\section{Keywords}

Animal Fat, Production, Biodiesel, Composition, Fuel Properties

\section{Introduction}

Biodiesel has largely been accepted as a suitable replacement for petroleum diesel on basis of its advantages over the later. The advantages include higher efficiency, relatively low emission profile, higher cetane number, renewability, lower sulfur content and safety of handling. However the obstacle to its full commercial application is the cost of production, with raw material cost estimated to be in the range of $70 \%-95 \%$ of total production cost [1] [2]. To avoid competition with food, other feedstock oils beside edible oils have been explored. These include waste cooking oil, non-edible plant oils such as jatropha oil, by-products from edible-oil refineries, waste animal and chicken fats. Use of this perceived cheap resource is envisaged to improve production economy of biodiesel fuel [3]. 
The most common method of processing oils into biodiesel is the transesterification reaction of oil/fat with primary alcohols such as methanol and ethanol in the presence of acid or alkali catalyst to produce fatty acid methyl or ethyl esters and glycerol as a by-product [4] [5]. Transesterification reaction is influenced by several factors that include free fatty acid content, feedstock type and composition, water content in the oil, type of alcohol used and amount, reaction temperature and pressure, type of catalyst used, and intensity of agitation. The American Standard for Testing of Materials (ASTM D 6751-02) and European Standard (EN14214) provide the required specifications for a fatty acid ester product to be classified as "biodiesel fuel" (B100) or for use in blends with any petroleum-derived diesel fuel. From their study, Glenn et al. [6] and Van Gerpen et al. [7] showed that animal fats perform better in biodiesel production than other substrates. Common animal fats (tallow) and lard are used for biodiesel because they are largely composed of saturated fatty acids which can be processed easily. Another advantage is that biodiesel derived from animal fats is in high cetane numbers, leading to better diesel engine performance and reduced emissions. Animal fat can be processed into biodiesel usually by esterification and transesterification processes using a common alkaline catalyst such as sodium hydroxide $(\mathrm{NaOH})$ or potassium hydroxide $(\mathrm{KOH})$. The operating temperature for processing animal fat should be kept below $60^{\circ} \mathrm{C}$ to avoid evaporation of methanol, which boils at approximately $60^{\circ} \mathrm{C}$. Too much catalyst should not be used when processing animal fat into biodiesel to avoid formation of excess soap which is detrimental to the process. The more FFA in the animal feedstock, the more soap is formed resulting in production loss.

\section{Feedstock}

In Botswana, people and cattle population have been inseparably linked for hundreds of years, and cattle form part of the fabric of everyday life. The raising of cattle touches almost all of the population, with cattle outnumbering people by two to one [8]. Urban dwellers and rural communities alike have some involvement and contact on a daily basis with cattle grazing on the veld. The Botswana cattle industry uses free range and natural farming methods, which ensure full flavoured, lean beef of highest quality. Botswana's land and its sub-tropical and semi-arid climate are ideally suited for cattle farming. The country boasts of between 2.5 to 2.8 million head of cattle. Botswana Meat Commission (BMC) is the main abattoir with three branches located in Lobatse (main), Francistown and Maun. The daily production of tallow at Lobatse abattoir ranges between $4000 \mathrm{~kg}$ and $11,500 \mathrm{~kg}$ [8]. Notwithstanding anticipated recovery levels for this substrate as well as any preparatory steps prior to biodiesel production process, the quantities of tallow available from Botswana's beef industry present a very substantial potential feedstock for biodiesel production that demand exploration.

In the current manuscript, pilot experimental results are presented on production, chemical composition and physicochemical fuel properties of biodiesel 
synthesized from tallow of Botswana's beef industry. Since the project is ongoing, other fuel properties such as performance and emissions shall be presented in subsequent publications.

\section{Materials and Methods}

\subsection{Biodiesel Production}

Production of biodiesel from beef fat involves three main stages namely tallow rendering from beef fat, a two stage process to produce fatty acid methyl esters (FAME) and separation of the reaction products.

\subsubsection{Tallow Rendering}

Beef fat (800 g), Figure 1, was shredded into smaller pieces and then charged into a pot for melting. The pot was heated by an electric burner. Shredding was performed to accelerate fat melting process. The process took about 60 minutes to get almost all the fat melted. The hot melted tallow (oil) was then strained from the residue using a sieve. Figure 2 shows melted tallow after separation from residues, ready for conversion to biodiesel.

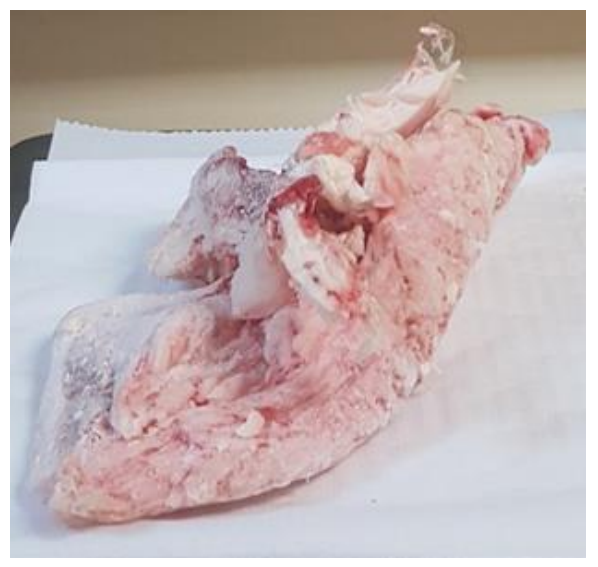

Figure 1. Beef fat.

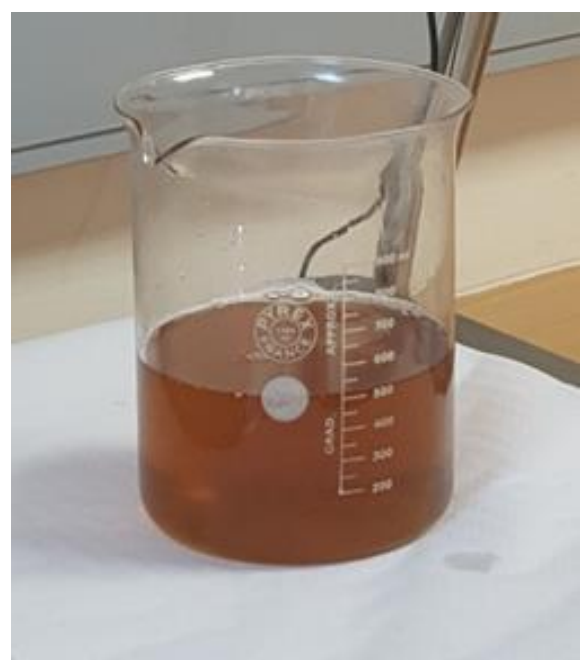

Figure 2. Beef tallow. 


\subsubsection{Transesterification}

Since the substrate to be utilized was tallow, a two stage process to produce biodiesel was required due to the high content of free fatty acids (FFA) of this substrate. The FFAs in tallow, which can be as high as $10 \%$, have to be reduced to below $2 \%$ to produce biodiesel of the quality required by either European or American standards [9]. Therefore the two stage process utilized consists of:

1) An initial esterification process where the tallow is mixed and heated with $2 \%$ by volume sulphuric acid $\left(\mathrm{H}_{2} \mathrm{SO}_{4}\right)$, allowed to settle, and the initial glycerol by-product drained off. This treatment reduces the FFAs to the required level (1.6\% in the current case).

2) The main process of trans-esterification, where the resultant tallow is then mixed and heated with the required percentages by volume of Methanol and catalyst.

In the second stage, $400 \mathrm{~g}$ of tallow at a temperature of about $60^{\circ} \mathrm{C}$ was charged to a $5000 \mathrm{ml}$ three neck glass flask reactor. A solution of $300 \mathrm{ml}$ of methanol of $99.5 \%$ purity and $6 \mathrm{~g}$ of potassium hydroxide pellets of $98 \%$ purity as catalyst was prepared and charged to the reaction vessel. The reactor was tightly closed and placed on a heating mantle and a temperature of approximately $60^{\circ} \mathrm{C}$ was maintained throughout the reaction process. The transesterification reaction was carried out for one hour with agitation by the stirrer to ensure adequate and homogeneous mixing throughout the reaction process. Adequate mixing was necessary since methanol has low solubility in tallow. The glass flask reactor was sealed to reduce the loss of methanol during the reaction process. A condenser was used to keep the methanol within the reactor. Figure 3 presents a schematic experimental set up of the process.

\subsubsection{Separation}

The products of the transesterification reaction (FAME and glycerol) are immiscible and are both in liquid form, with glycerol having higher density than FAME. On basis of difference in density, separation of the reaction products was done using a separating funnel. The set up was left for 24 hours to ensure complete separation. Two distinct layers were observed, the upper layer being the

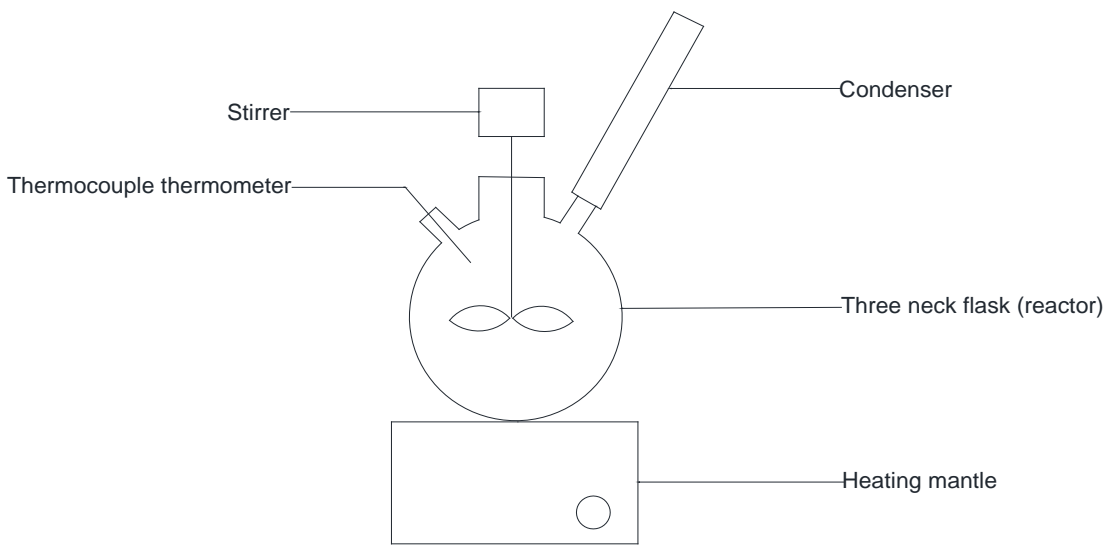

Figure 3. Schematic experimental set up of the transesterification process. 
methyl ester (biodiesel) and the lower layer was glycerol, due to its higher specific gravity. Glycerol was drained off from the bottom of the reaction vessel until only biodiesel (and possibly traces of unreacted methanol) remained. The biodiesel was then water washed twice with distilled water to ensure removal of all traces of glycerol. A rotary vacuum evaporator was used to recover the unreacted alcohol from the biodiesel [10].

The petroleum diesel fuels used for comparison were purchased from a local Shell Petrol Station and had the following properties:

Diesel $50 \mathrm{ppm}$-density of $831 \mathrm{~kg} / \mathrm{m}^{3}$, viscosity of $2.3 \mathrm{~mm}^{2} / \mathrm{s}$ at $40^{\circ} \mathrm{C}$, acidity of $0.2 \mathrm{mg} \mathrm{KOH} / \mathrm{g}$, calorific value of $46.5 \mathrm{MJ} / \mathrm{Kg}$, flash point of $79^{\circ} \mathrm{C}$, cloud point of $2^{\circ} \mathrm{C}$ and pour point of $-12^{\circ} \mathrm{C}[10]$.

Diesel $500 \mathrm{ppm}$-density of $833 \mathrm{~kg} / \mathrm{m}^{3}$, viscosity of $2.3 \mathrm{~mm}^{2} / \mathrm{s}$ at $40^{\circ} \mathrm{C}$, acidity of $0.3 \mathrm{mg} \mathrm{KOH} / \mathrm{g}$, calorific value of $46.4 \mathrm{MJ} / \mathrm{Kg}$, flash point of $81^{\circ} \mathrm{C}$, cloud point of $1{ }^{\circ} \mathrm{C}$ and pour point of $-10^{\circ} \mathrm{C}$.

\subsection{Chemical Characterization}

Chemical analysis was done to identify esters present in tallow biodiesel sample. The method involved analyzing standard (reference) samples, generating calibration curves for esters identified in the standard samples, and identifying and quantifying esters present in the biodiesel sample [11].

\subsubsection{Gas Chromatograph Conditions}

One micro litre $(1 \mu \mathrm{l})$ of tallow biodiesel sample extract was injected into the system using an auto-injector. The injector temperature was set at $260^{\circ} \mathrm{C}$ in the splitless mode. Helium was used as the carrier gas at a flow rate of $1 \mathrm{ml} / \mathrm{min}$. Separation was achieved using a 30 meter DB5-MS column. The oven temperature was kept at the initial $100^{\circ} \mathrm{C}$ for $2 \mathrm{~min}$, and then gradually increased from $100^{\circ} \mathrm{C}$ to $290^{\circ} \mathrm{C}$ at a rate of $10^{\circ} \mathrm{C}$ per min. The total run time was approximately 35 $\min$.

\subsubsection{Mass Spectrometer Conditions}

The mass spectrometer (MS) conditions that were employed were a positive polarity of electron ionisation (EI), a source temperature of $180^{\circ} \mathrm{C}$, and an emission current of $359 \mu \mathrm{A}$. Other MS conditions including electron energy and resolution were set by the system's auto tune function. Detection was by the micro channel plate detector (MCP) whose voltage was set at $2700 \mathrm{~V}$. The sample composition was identified and quantified using the NIST (2005) mass spectral library using a combination of the Masslynx acquisition/data analysis software and the AMDIS by NIST.

\subsection{Flash Point Measurement}

The flash points of tallow biodiesel and petroleum diesel fuel test samples were determined using an automated Pensky-Martens Closed Cup Tester according to the ASTM D93 test method. A brass test cup (of specified dimensions) was filled to the inside mark with fuel test specimen and fitted with a cover (of speci- 
fied dimensions). Settings of expected flash point value, sample name and procedure selection were made to complete the instrument setup. Procedure A was used for petroleum diesel while procedure $\mathrm{C}$ was used for tallow biodiesel (B100). The experiment was run and the test cup was heated while the specimen was agitated by a stirrer at a pre-determined rate according to the specified procedure. An ignition source was directed into the test cup at regular intervals with simultaneous interruption of the stirring, until a flash was detected. Each test sample was first analyzed using the search (SPE) procedure since flash points of the samples were unknown. The normal mode of the procedure was then used to validate the results [10].

\subsection{Viscosity Analysis}

Tallow biodiesel and petroleum diesel fuel samples were analyzed using a Fungilab Premium Series (PREL 401024) viscometer coupled to a Thermo Fisher Scientific heating bath circulator. The procedure of measurement is detailed in Gandure et al., 2015.

\subsection{Energy Content Analysis}

The calorific values of tallow biodiesel and petroleum diesel samples were determined using the IKA C200 Calorimeter system whose main components include the basic device, decomposition vessel, ignition adapter, combustion crucible and oxygen filling point. The system has automatic data acquisition through the CalWin calorimeter software which handles calculations for the calorific values of samples. Details of procedure are articulated in [11].

\section{Results and Discussion}

\subsection{Tallow Biodiesel Yield}

Biodiesel yield is defined in the current context as the percentage of volume of biodiesel separated from glycerol after transesterification to volume of tallow used in the process. In this case, $505 \mathrm{ml}(400 \mathrm{~g})$ of tallow was used in the transesterification process, and $470 \mathrm{ml}$ of biodiesel was recovered from the separating funnel.

$$
\text { Yield }=(470 / 505) \times 100=93 \%
$$

The biodiesel yield of $93 \%$ from tallow is comparable to yields from most widely accepted plant kernel oils. Tallow biodiesel yield is therefore deemed sufficiently high to justify exploration of tallow as a potential feedstock for production of biodiesel in Botswana. One unique advantage of tallow biodiesel production is quick separation of biodiesel from glycerol, which largely takes place in the first 10 minutes of standing in the separation funnel.

\subsection{Chemical Composition}

The chemical composition of tallow biodiesel was analyzed according to the procedure described in Section 2.2. Table 1 presents ester composition of tallow 
Table 1. Ester composition of Tallow biodiesel.

\begin{tabular}{ccc}
\hline Compound & Formula & Concentration (\% of Total) \\
\hline Methyl margarate & $\mathrm{C}_{18} \mathrm{H}_{36} \mathrm{O}_{2}$ & 1.692 \\
$\begin{array}{c}\text { Methyl 10-trans, } \\
\text { 12-cis-octadecadienoate }\end{array}$ & $\mathrm{C}_{19} \mathrm{H}_{34} \mathrm{O}_{2}$ & 1.938 \\
Methyl palmitoleate & $\mathrm{C}_{17} \mathrm{H}_{32} \mathrm{O}_{2}$ & 2.426 \\
Methyl oleate & $\mathrm{C}_{19} \mathrm{H}_{36} \mathrm{O}_{2}$ & 36.368 \\
Methyl stearate & $\mathrm{C}_{19} \mathrm{H}_{38} \mathrm{O}_{2}$ & 25.657 \\
Methyl palmitate & $\mathrm{C}_{17} \mathrm{H}_{34} \mathrm{O}_{2}$ & 27.680 \\
Methyl myristate & $\mathrm{C}_{15} \mathrm{H}_{30} \mathrm{O}_{2}$ & 4.238 \\
\hline
\end{tabular}

biodiesel.

The ester composition of tallow biodiesel indicates that the most abundant compounds are methyl oleate, methyl palmitate and methyl stearate with concentrations of $36.4 \%, 27.7 \%$ and $25.7 \%$ of total respectively. These three compounds, constituting about $90 \%$ of total, are all long chain compounds that are largely saturated, with a small degree of unsaturation. This characteristic ester composition of a biodiesel fuel has a strong influence on fuel properties. Fuel properties of oil and hence derived biodiesel improve in quality with increase in carbon chain length and decrease as the number of double bonds increase, except for cold flow properties. Thus, properties such as heat of combustion, cetane number, freeze temperature, viscosity and oxidative stability increase as the chain length increases and decrease as the number of double bonds increases. A fuel whose constituent mixture of compounds is fully saturated will depict better oxidative stability and higher cetane number, but poor cold flow properties. The small degree of unsaturation depicted by double bonds in methyl oleate, methyl palmitate and methyl stearate is significant as double bonds inhibit crystallization, thereby lowering cloud and pour points of the fuel. A low cloud point is a desirable fuel property as it ensures that a fuel remains in the liquid phase at low temperatures. Thus tallow biodiesel has a good properties trade-off between cold flow properties, oxidative stability and cetane number. Flash point analysis of tallow biodiesel is presented in Section 3.3.

\subsection{Flash Point Analysis}

Experimental data were recorded as described in Section 2.3. After running five experiments for each fuel specimen and computing average values, results obtained for flash point of tallow biodiesel, $50 \mathrm{ppm}$ petroleum diesel and $500 \mathrm{ppm}$ petroleum diesel fuels are presented in Figure 4.

The ASTM D-6751 and EN 14214 biodiesel standards stipulate minimum values of $130^{\circ} \mathrm{C}$ and $120^{\circ} \mathrm{C}$ respectively for flash point. The results demonstrate that tallow biodiesel meets specifications of both American and European standards, and is a much safer fuel to handle than petroleum diesels. Viscosity analysis of tallow biodiesel is presented in Section 3.4. 


\subsection{Viscosity Analysis}

Evaluation of viscosity of fuels is vital in order to determine viability of use in diesel engines as viscosity influences fuel atomization and hence quality of combustion. The viscosity profiles of tallow biodiesel and petroleum diesel fuels were analyzed. Figure 5 shows profiles of viscosity variation with temperature for the two petroleum diesel fuels and biodiesel, with each data point representing an average of four viscosity measurements.

From Figure 5, it can be deduced that viscosity profiles of both tallow biodiesel and petroleum diesel fuels (used in this study) meet requirements of the American Standards (ASTM D-6751), 1.8 - 6.0 cSt, but are largely lower than the requirements of the European standards (EN 14214), $3.5-5.0 \mathrm{cSt}$, at $40^{\circ} \mathrm{C}$. The viscosity at $40^{\circ} \mathrm{C}$ indicates that tallow biodiesel $\left(2.71 \mathrm{~mm}^{2} / \mathrm{s}\right)$ has marginally better lubricity than the two petroleum diesel fuels $\left(2.57 \mathrm{~mm}^{2} / \mathrm{s}\right.$ and $\left.2.40 \mathrm{~mm}^{2} / \mathrm{s}\right)$ and is likely to have a better combustion profile when used as a fuel in a diesel engine. The heat of combustion of tallow biodiesel is presented in Section 3.5.

\subsection{Heat of Combustion}

Heat of combustion, or energy content, refers to the thermal energy that is liberated upon combustion of a fuel. In the study conducted to analyze energy content

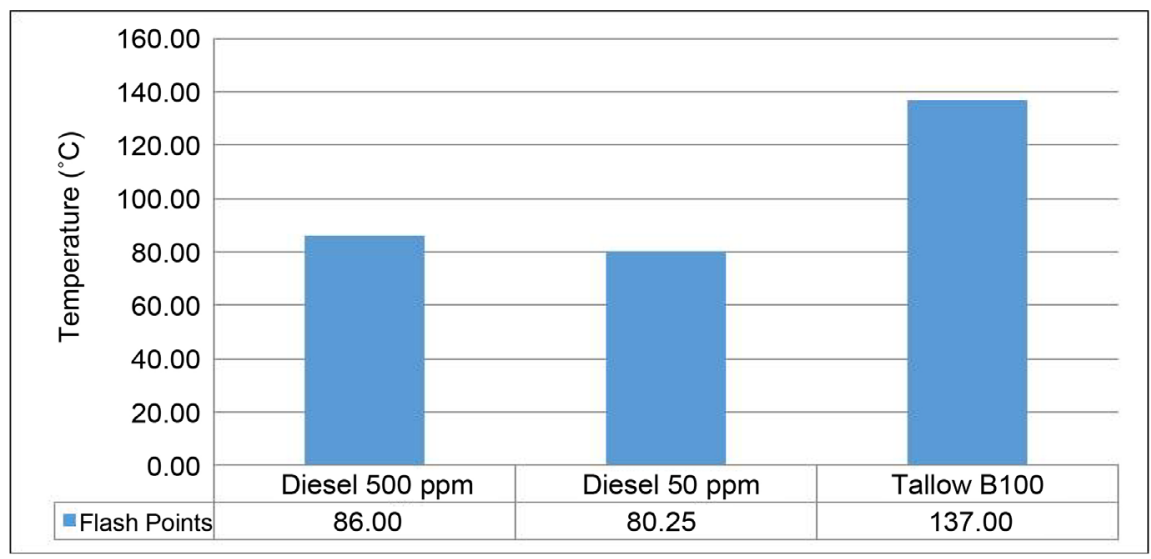

Figure 4. Flash points of petroleum diesel and tallow biodiesel fuels.

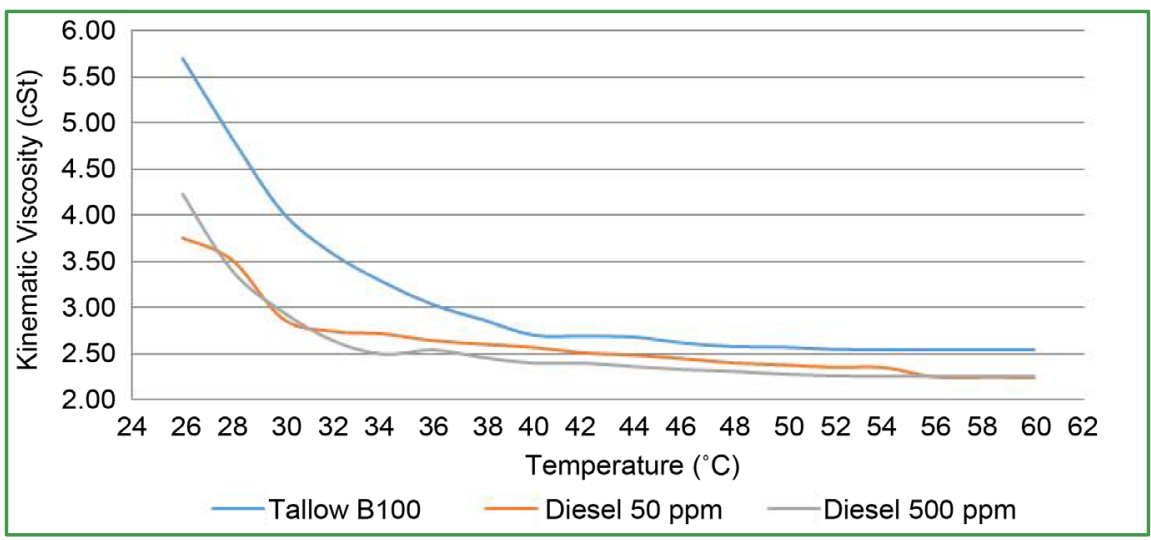

Figure 5. Viscosity variation with temperature. 
levels of tallow biodiesel and petroleum diesel fuels, the experimental data were recorded as described in Section 2.5. After running four experiments for each of the three fuel samples, computation of mean values yielded calorific values presented in Figure 6.

Biodiesel fuels are mixtures of fatty acids with different degrees of saturation, and energy content decreases with increase in the degree of unsaturation. This is unlike petroleum diesel which contains aromatics. Thus the lower energy content of tallow biodiesel relative to petroleum diesel fuels is to be expected on this basis. However, energy content of $39.31 \mathrm{MJ} / \mathrm{kg}$ for tallow biodiesel is closely comparable to $39.61 \mathrm{MJ} / \mathrm{kg}$ and $44.90 \mathrm{MJ} / \mathrm{kg}$ for the two petroleum diesel fuels.

\section{Economic Feasibility of Using Tallow as Biodiesel Feedstock}

The future outlook of beef tallow biodiesel fuel is bright on basis of abundance and insignificant use for food. As discussed in Section 1.1, Botswana has a vast abundance of cattle that approximates three (3) million heads. In the production of biodiesel, a major economic factor that should be considered with respect to input costs is feedstock, which is estimated at approximately $80 \%$ of the total operating cost [12].

Other important costs relate to geographical location of feedstock (abattoirs), variability in fat production across seasons of the year, labor and production inputs including methanol and catalyst. These costs are functions of prices of the fat and the size and type of the production facility. Other important factors that can impact the production cost of tallow biodiesel are the yield and value of the by-products of the production process. These include glycerol that is used in production of soap and as a pharmaceutical medium. Production of biodiesel from tallow will also have obvious positive social impacts. It provides a market for farmers and employment for many families in the supply chain. Furthermore, a local abundance of cattle implies a substantial reduction in overall costs of producing biodiesel since there is no importation of feedstock.

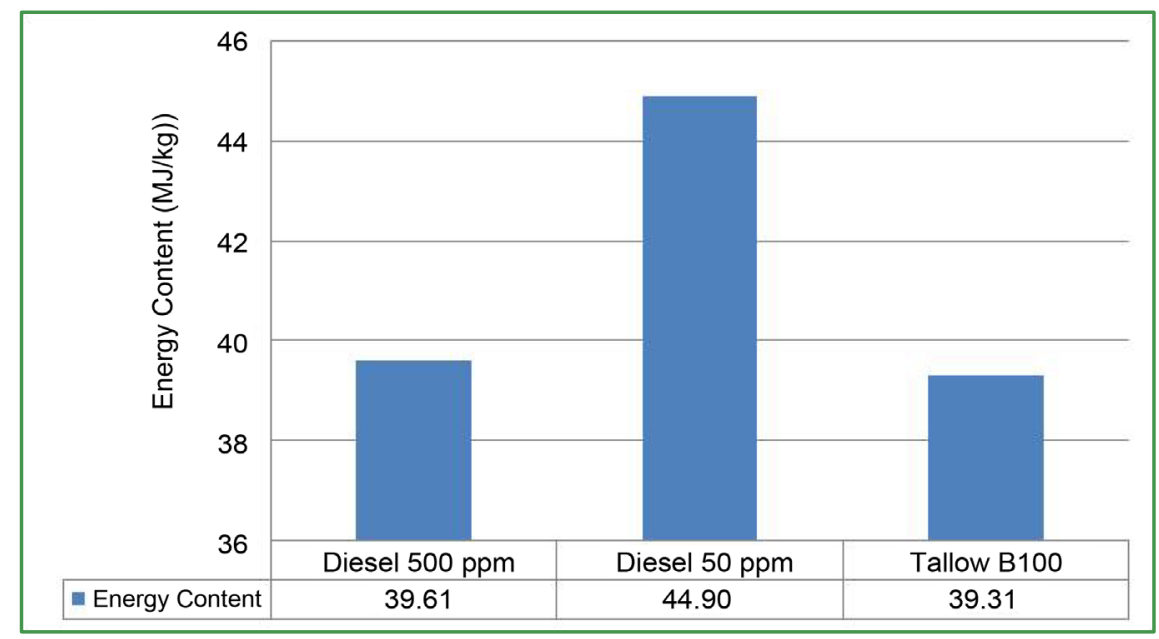

Figure 6. Energy content of fuels. 
On basis of abundant availability of feedstock and results discussed in the current manuscript, tallow biodiesel is recommended for production in Botswana.

\section{Conclusions}

The following conclusions can be made from the experimental work discussed in this manuscript:

1) The chemical composition of tallow biodiesel is typical of a biodiesel fuel, with $90 \%$ constituted by methyl oleate, methyl palmitate and methyl stearate which are principal constituent compounds of a biodiesel fuel.

2) Beef tallow biodiesel production depicted a yield of $93 \%$ with a unique short separation period of approximately 10 minutes.

3) The viscosity of beef tallow biodiesel at $40^{\circ} \mathrm{C}$ meets ASTMD6751 international biodiesel standards and is closely comparable to that of petroleum diesel.

4) The heat of combustion of beef tallow biodiesel was found to be $12.4 \%$ and $0.8 \%$ lower than $50 \mathrm{ppm}$ and $500 \mathrm{ppm}$ petroleum diesel fuels respectively. It however has higher heat of combustion than biodiesel fuels derived from most vegetable oils.

The high flash point $\left(137^{\circ} \mathrm{C}\right)$ of beef tallow biodiesel is typical of a biodiesel fuel and makes it safe to transport and handle.

\section{References}

[1] Leung, D.Y.C., Wu, X. and Leung, M.K.H. (2010) A Review on Biodiesel Production Using Catalyzed Transesterification. Applied Energy, 87, 1083-1095. https://doi.org/10.1016/j.apenergy.2009.10.006

[2] Balat, M. (2011) Potential Alternatives to Edible Oils for Biodiesel Production-A Review. Energy Conservation Management, 52, 1479-1492. https://doi.org/10.1016/j.enconman.2010.10.011

[3] Moraes, M.S.A., Krause, L.C., da Cunha, M.E., Faccini, C.S., de Menezes, E.W., Veses, R.C. et al. (2008) Tallow Biodiesel: Properties Evaluation and Consumption Tests in a Diesel Engine. Energy Fuel, 22, 1949-1954.

[4] Zhang, Y., Dube, M.A., Mclean, D.D. and Kates, M. (2003) Biodiesel Production from Waste Cooking Oil: 2. Economic Assessment and Sensitivity Analysis. Bioresources Technology, 90, 229-240. https://doi.org/10.1016/S0960-8524(03)00150-0

[5] Bautista, L.F., Vicente, G., Bodriguez, R. and Pacheco, M. (2009) Optimisation of FAME Production from Waste Cooking Oil for Biodiesel Use. Biomass and Bioenergy, 33, 862-872. https://doi.org/10.1016/j.biombioe.2009.01.009

[6] Glenn, E.P., Brown, J.J. and O'Leary, J.W. (1998) Irrigating Crops with Seawater. Scientific American, 279, 76-81. https://doi.org/10.1038/scientificamerican0898-76

[7] Van Gerpen, J. et al. (2004) Biodiesel Production Technology. Subcontractor Report NREL/SR-510-36244, Subcontract No. ACO-2-35016-01.

[8] BMC, 2016. http://www.bmc.bw/

[9] Tesfa, B., Mishra, R., Gu, F. and Powles, N. (2010) Prediction Models for Density and Viscosity of Biodiesel and Their Effects on Fuel Supply System in CI Engines. Renewable Energy, 35, 2752-2760. https://doi.org/10.1016/j.renene.2010.04.026

[10] Gandure, J., Ketlogetswe, C. and Temu, A. (2013) Fuel Properties of Jatropha Me- 
thyl Ester and Its Blends with Petroleum Diesel. ARPN Journal of Engineering and Applied Sciences, 8, 900-908.

[11] Gandure, J., Ketlogetswe, C. and Temu, A. (2015) Experimental Investigations on Fuel Properties of Biodiesel Derived from Tylosema Esculentum Kernel Oil. International Journal of Green Energy, 12, 620-634. https://doi.org/10.1080/15435075.2013.872115

[12] Demirbas, A. (2009) Progress and Recent Trends in Biodiesel Fuels. Energy Conversion and Management, 50, 14-34.

https://doi.org/10.1016/j.enconman.2008.09.001

\section{Scientific Research Publishing}

Submit or recommend next manuscript to SCIRP and we will provide best service for you:

Accepting pre-submission inquiries through Email, Facebook, LinkedIn, Twitter, etc. A wide selection of journals (inclusive of 9 subjects, more than 200 journals) Providing 24-hour high-quality service User-friendly online submission system Fair and swift peer-review system Efficient typesetting and proofreading procedure Display of the result of downloads and visits, as well as the number of cited articles Maximum dissemination of your research work

Submit your manuscript at: http://papersubmission.scirp.org/

Or contact epe@scirp.org 